\title{
Diversity of fall armyworm, Spodoptera frugiperda and their gut bacterial community in Kenya
}

\author{
Joseph N Gichuhi ${ }^{1}$, Subramanian Sevgan ${ }^{1}$, Fathiya Khamis ${ }^{1}$, Johnnie Van den Berg ${ }^{2}$, Hanalenne Du Plessis $^{2}$, \\ Sunday Ekesi ${ }^{1}$, Jeremy Herren ${ }^{\text {Corresp. } 1,3}$ \\ 1 International Centre of Insect Physiology and Ecology (ICIPE), Nairobi, Kenya \\ Unit for Environmental Sciences and Management, North-West University, Potchefstroom, South Africa \\ 3 MRC-University of Glasgow Centre for Virus Research, Henry Wellcome Building, Glasgow, United Kingdom \\ Corresponding Author: Jeremy Herren \\ Email address: jherren@icipe.org
}

Background The invasive fall armyworm (FAW), Spodoptera frugiperda (J.E. Smith) is a polyphagous pest that causes widespread damage particularly to maize and sorghum in Africa. The microbiome associated withS. frugiperda could play a role in the insects' success and adaptability. However, bacterial communities in $S$. frugiperda remain poorly studied.

Methods We investigated the composition, abundance and diversity of microbiomes associated with larval and adult specimens of $S$. frugiperda collected from four maize growing regions in Kenya through high throughput sequencing of the bacterial $16 S$ rRNA gene. The population structure of $S$. frugiperda in Kenya was assessed through amplification of the mitochondrial cytochrome oxidase subunit I gene.

Results We identified Proteobacteria and Firmicutes as the most dominant bacterial phyla and lesser proportions of Bacteroidetes and Actinobacteria. We also observed differences in bacterial microbiome diversity between larvae and adults that are a likely indication that some prominent larval bacterial groups are lost during metamorphosis. However, several bacterial groups were found in both adults and larvae suggesting that they are transmitted across developmental stages. Reads corresponding to several known entomopathogenic bacterial clades as well as the fungal entomopathogen, Metarhizium rileyi, were observed. Mitochondrial DNA haplotyping of the $S$. frugiperda population in Kenya indicated the presence of both 'Rice' and 'Corn' strains, with a higher prevalence of the 'Rice' strain. 
1 Diversity of fall armyworm, Spodoptera frugiperda and their gut bacterial community in

2 Kenya

3

4 Joseph Gichuhi ${ }^{1}$, Sevgan Subramanian ${ }^{1}$, Fathiya M. Khamis ${ }^{1}$, Johnnie Van den Berg ${ }^{2}$,

5 Hannalene du Plessis ${ }^{2}$, Sunday Ekesi ${ }^{1}$, and Jeremy K Herren ${ }^{1,3}$

6

$7 \quad{ }^{1}$ International Centre of Insect Physiology and Ecology (ICIPE), Nairobi, Kenya

82 Unit for Environmental Sciences and Management, North-West University,

9 Potchefstroom, South Africa,

$10{ }^{3}$ MRC-University of Glasgow Centre for Virus Research, Henry Wellcome Building,

11 Glasgow, United Kingdom

13 Corresponding Author:

14 Jeremy Herren

15 International Centre of Insect Physiology and Ecology (ICIPE), Nairobi, Kenya

16 Email address: jherren@icipe.org

\section{Abstract}

19 Background

20 The invasive fall armyworm (FAW), Spodoptera frugiperda (J.E. Smith) is a

21 polyphagous pest that causes widespread damage particularly to maize and sorghum in

22 Africa. The microbiome associated with S. frugiperda could play a role in the insects' 
23 success and adaptability. However, bacterial communities in S. frugiperda remain

24 poorly studied.

25 Methods

26 We investigated the composition, abundance and diversity of microbiomes associated

27 with larval and adult specimens of $S$. frugiperda collected from four maize growing

28 regions in Kenya through high throughput sequencing of the bacterial 16S rRNA gene.

29 The population structure of $S$. frugiperda in Kenya was assessed through amplification

30 of the mitochondrial cytochrome oxidase subunit I gene.

\section{Results}

We identified Proteobacteria and Firmicutes as the most dominant bacterial phyla and

lesser proportions of Bacteroidetes and Actinobacteria. We also observed differences in bacterial microbiome diversity between larvae and adults that are a likely indication that some prominent larval bacterial groups are lost during metamorphosis. However, several bacterial groups were found in both adults and larvae suggesting that they are transmitted across developmental stages. Reads corresponding to several known entomopathogenic bacterial clades as well as the fungal entomopathogen, Metarhizium rileyi, were observed. Mitochondrial DNA haplotyping of the S. frugiperda population in Kenya indicated the presence of both 'Rice' and 'Corn' strains, with a higher prevalence 41 of the 'Rice' strain.

\section{Introduction}


44 Invasions by exotic pests can have major detrimental effects on agricultural production 45 and natural resources (Huber et al., 2002). The fall armyworm, Spodoptera frugiperda

46 (J. E. Smith) (Lepidoptera: Noctuidae) is a polyphagous pest that is native to tropical 47 regions of the western hemisphere, where it is known for its ability to cause economic damage to several crop species. In 2016, S. frugiperda was first detected in West Africa 49 (Goergen et al., 2016), and since then this pest has rapidly spread across the continent (Day et al. 2017; Nagoshi et al. 2018; Rwomushana et al. 2018). By 2018, S. frugiperda was reported in all countries in Sub-Saharan Africa except Djibouti and Lesotho (Rwomushana et al., 2018). Furthermore, S. frugiperda also has now reached the continent of Asia (Deole \& Paul, 2018; Sisodiya et al., 2018). Maize and other economically important food crops in these regions are extensively damaged by $S$. frugiperda larvae (Day et al., 2017) causing extensive economic losses and threatening food security. Genetic characterizations have supported the initial postulation that this pest species exists in two subpopulations called the 'Rice' and 'Corn' strains that are preferentially associated either with smaller grasses (such as rice and bermudagrass) or with larger grasses (such as sorghum and maize) respectively (Nagoshi \& Meagher, 2004). Strain composition in populations of this pest may therefore have ramifications on the variety of crops at risk of infestation (Nagoshi et al., 2019).

There is a lack of information about $S$. frugiperda-host plant interactions and other factors that may be leading to the rapid spread of $S$. frugiperda in the geographic regions that have recently been invaded. Many of the control measures used in the western hemisphere (e.g. transgenic maize, chemical insecticides) might not be readily 
67 available and economically viable for subsistence farmers in Africa. Furthermore, the 68 use of highly hazardous pesticides is not considered a sustainable long term control

69 measure for any pest (FAO, 2018). In addition, S. frugiperda have been reported to

70 evolve resistance to most chemical insecticides (e.g. pyrethroids, organophosphates

71 and carbamates) (Yu 1991) and to transgenic maize that are used in its control (Jakka

72 et al. 2016; Banerjee et al. 2017; Flagel et al. 2018; Botha et al. 2019). As a

73 consequence, there is a great need for alternative, cost-effective control strategies for

74 S. frugiperda (FAO, 2018).

75

76 A recent survey in Ethiopia, Kenya and Tanzania indicated that $S$. frugiperda has

77 established interactions with indigenous parasitoid species (Sisay et al., 2018) that

78 could be harnessed for biological control. A study on S. frugiperda host plant

79 interactions in East Africa has also suggested a climate adapted push-pull system

80 (Midega et al., 2018) and maize-legume intercropping (Hailu et al., 2018) for

81 management of pests including fall armyworm on maize farms. However, many factors

82 related to $S$. frugiperda rapid spread, host plant interactions, bio-ecology and insect-

83 microbiome interactions in the African region remain poorly understood.

84

85 Insect microbiomes can have important consequences for the outcome of insect pest-

86 natural enemies- host plant interactions (Ferrari, Vavre \& Lyon, 2011). Strategies that

87 involve modifying insect microbiomes are currently being evaluated for control and

88 management of pests and vectors of plant diseases (Crotti et al., 2012; Perilla-henao \&

89 Casteel, 2016; Arora \& Douglas, 2017; Beck \& Vannette, 2017). Insect microbiomes 
90 play a key role in the adaptation of insects to their environment and are therefore a

91 major and often poorly understood determinant of the host plant and geographic range

92 of insect pests (Su, Zhou \& Zhang, 2013). In general, a greater diversity of microbial

93 symbionts exist within the insect's gut lumen, while few others exist inside cells of the

94 host, or on the cuticle (Douglas, 2016). Gut microbial symbionts are known to influence

95 their host's nutrition, usually by promoting digestion and availability of nutrients

96 (Douglas, 2009). These symbionts can also modulate the immune response and

97 accessibility of the host to invading organisms, and therefore have direct or indirect

98 effects on host susceptibility to parasites and pathogens (Garcia et al., 2010; Mclean \&

99 Godfray, 2015; Ubeda, Djukovic \& Isaac, 2017). Previous studies have also identified

100 important roles of bacterial symbionts in the interactions between phytophagous insects

101 and host plants (Frago, Dicke \& Godfray, 2012; Biere \& Bennett, 2013; Brady \& White,

102 2013). In addition, microbial symbionts can break down complex molecules such as

103 insecticides and promote insecticide resistance (Kikuchi et al. 2012; Xia et al. 2018). It

104 is also notable that pathogenic bacteria can reside in host guts, only initiating or

105 facilitating pathogenesis under certain conditions (Wei et al., 2017). Studying the gut

106 microbiome is not only important from the standpoint of understanding mutualistic

107 relationships but also for laying the foundation for future projects aimed at developing

108 microbial biocontrol agents.

109

110 There are an increasing number of studies examining the microbial diversity of

111 lepidopterans. While in some of the assessed species consistent bacterial communities

112 have been observed in both field and laboratory collected populations as well as in 
113 insects reared on different diets (Broderick et al., 2004; Xiang et al., 2006; Pinto-Tomás

114 et al., 2011), other studies reported no host specific resident communities that occurred,

115 regardless of the insect diet (Hammer et al., 2017). It is possible that lepidopterans are

116 less prone to forming robust 'core' microbiomes due to several factors: 1) very high $\mathrm{pH}$

117 in the midgut, 2) low retention time of food, 3) lack of microbe housing structures in the

118 intestinal tract, and 4) continual replacement of the peritrophic matrix (Hammer et al.,

119 2017). Nevertheless, bacterial communities do continually associate with lepidopterans

120 and influence a variety of important host processes (Broderick, Raffa \& Handelsman,

121 2006; Anand et al., 2010; Wang et al., 2017).

122

123 Relatively few studies have assessed the Spodoptera-associated gut microbiome. In a 124 recent study, the microbial diversity of Spodoptera exigua (Hübner) (Lepidoptera:

125 Noctuidae) was examined by 165 rDNA sequence profiling (Gao et al., 2018). In 126 Spodoptera exigua, the dominant bacterial clades are Proteobacteria and Firmicutes, 127 with the predominant genus in larvae being Enterococcus. In S. frugiperda, previous 128 studies have isolated several bacterial strains using culture-dependent methods (De 129 Almeida et al. 2017; Acevedo et al. 2017).

131 In this study, we used $16 \mathrm{~S}$ rDNA sequence profiling to characterize the diversity of

132 bacteria associated with populations of $S$. frugiperda in Kenya and assessed the 133 prevalence of the $S$. frugiperda strains in these populations using mitochondrial $\mathrm{COI}$ 134 gene sequences. Specifically, we characterized the structure of the circulating $S$. 135 frugiperda populations in Kenya as well as the gut bacterial communities derived from 
136 both larval and adult specimens collected in different agro-ecological zones.

137 Understanding pest population structures is important for understanding invasion

138 patterns and planning with regards to strain-specific susceptibility of crops, whereas

139 characterizing pest-associated microbiomes is a useful foundation for exploring insect-

140 microbiome interactions that could be exploited to improve control strategies.

142 Materials \& Methods

\section{Insect collection}

144 Spodoptera frugiperda larvae were collected from infested maize fields in Kenya 145 between June and December 2017 at the following locations: Ngeria (N00.37024 146 E035.9862) and Burnt Forest (N00.22505 E035.42479) in Uasin Gishu County; Msamia, 147 Kitale (N00.98009 E034.97170) in Trans Nzoia County; Shimba Hills (S04.33228 148 E039.34361) in Kwale County and Chala Irrigation Scheme (S03.27338 E037.13816) 149 and Wundanyi (S03.337538 E038.33612) in Taita Taveta County. Part of the field 150 collected insects from each sampled region in Kenya were reared on fresh maize leaves 151 in ventilated cages to pupation and eclosion at $27^{\circ} \mathrm{C}$ and $60 \%$ humidity, while the rest 152 were stored in absolute ethanol at $-20^{\circ} \mathrm{C}$. We profiled the bacterial microbiome for 18 153 samples from four of these locations, whereas we included samples from all the 154 sampled locations for mtDNA haplotyping (Fig. 1).

155

156 DNA extraction and 16S rDNA sequencing

157 Guts from nine live stage 5-6 larvae and nine one-day old emerging adults from the 158 Kenya collected samples were dissected separately in phosphate buffered saline (PBS) 
159 following surface sterilization and used for DNA extraction. Insects were surface 160 sterilized in $70 \%$ ethanol, in $5 \% \mathrm{v} / \mathrm{v}$ sodium hypochlorite solution followed by 3 washes 161 in PBS for 3 minutes in each solution. Each dissected gut tissue was homogenized in 162 PBS using five $4 \mathrm{~mm}$ diameter ceramic beads in a $2 \mathrm{ml}$ microfuge tube, using a 163 TissueLyser II beadmill (Qiagen, Hilden, Germany). DNA was extracted using the 164 ISOLATE II Genomic DNA Kit (Bioline, London, UK) according to the manufacturer's 165 instructions. DNA extracted from gut samples was submitted for high throughput 166 sequencing targeting the $v 4$ region of the bacterial 16 s rRNA gene using the Illumina 167 Miseq platform (Center for Integrated Genomics, University of Lausanne, Switzerland). 168 Sequence reads were checked for quality using FastQC v 0.11.28 (Andrews, 2010) and 169 pre-processed to remove adapters and sequencing primers using Cutadapt v1.18 170 (Martin, 2011). Forward and reverse reads were imported into QIIME2-2018.11 (Boylen 171 et al., 2018). The deblur plugin (Amir et al., 2017) was used to further filter the reads 172 based on per base quality scores and merge the paired-end-reads and cluster reads 173 into operational taxonomic units (OTUs). Taxonomic assignment was done using the 174 blast classifier against the Silva132 reference database (Quast et al., 2013) at a 99\% 175 identity cut-off. OTU prevalence and variance based filtering as well as alpha and beta 176 diversity measures were applied to the data in the Microbial Analyst Marker Data 177 Profiling (Dhariwal et al., 2017). Shannon diversity indices were applied along with 178 Mann-Whitney and analysis of variance statistics in profiling alpha diversity between 179 sets of samples. Beta diversity was evaluated using Bray-Curtis and unweighted Unifrac 180 distances. Significance testing was done using permutational multivariate analysis of 181 variance (PERMANOVA) and visualization done through non-metric multidimensional 
182 scaling (NMDS) ordination. The empirical analysis of digital gene expression data in R

183 (edgeR) algorithm (Robinson, McCarthy \& Smyth, 2009) was used to evaluate

184 differential abundance of bacterial genera reads between sample groups. All sequence

185 reads were archived in the Sequence Read Archive (SRA) under the BioProject:

186 PRJNA521837.

187

188

mtDNA haplotyping

189

DNA was extracted from surface-sterilized whole insects using the ISOLATE II Genomic

190 DNA Kit (Bioline, London, UK) according to the manufacturer's instructions.

191

Mitochondrial COI gene sequences were amplified from insect DNA by PCR using the

192

primer LCO1490 and HCO2198 (Folmer et al., 1994). Reactions were set up in total

193

volumes of $10 \mu \mathrm{l}$ each, containing $5 \times$ MyTaq reaction buffer ( $5 \mathrm{mM}$ dNTPs, $15 \mathrm{mM}$

194

$\mathrm{MgCl} 2$, stabilizers and enhancers) (Bioline, London, UK), $2 \mu \mathrm{M}$ of each primer, $0.25 \mathrm{mM}$

195

MgCl2 (Thermo Fischer Scientific, Massachusetts, USA), $0.125 \mu$ I MyTaq DNA

196

polymerase (Bioline, London, UK), and $7.5 \mathrm{ng} / \mu \mathrm{l}$ of DNA template. These reactions

197

were set up in a Master cycler Nexus gradient thermo-cycler (Thermo Fischer Scientific,

Massachusetts, USA) using the following cycling conditions: initial denaturation for 2

199

min at $95^{\circ} \mathrm{C}$, followed by 40 cycles of $30 \mathrm{~s}$ at $95^{\circ} \mathrm{C}, 45 \mathrm{~s}$ at $50.6^{\circ} \mathrm{C}$ and 1 min at $72^{\circ} \mathrm{C}$,

200

then a final elongation step of $10 \mathrm{~min}$ at $72{ }^{\circ} \mathrm{C}$. PCR products were separated by $1 \%$

201

agarose gel electrophoresis and visualized by ethidium bromide staining and UV trans-

202 illumination. Direct sequencing was done for all host $\mathrm{mtCOI}$ gene and the sequences

203 deposited in the GenBank.

204 


\section{Results}

206 A total of 457501 sequence reads were retained after removal of spurious reads and all 207 reads shorter than 220 , where the median length of all sequences with a quality score 208 higher than 20. These sequences clustered into 1796 OTUs. Of these, 197 OTUs 209 survived low count and interquartile range-based variance filtering to eliminate OTUs 210 that could arise from sequencing errors and contamination. OTUs initially characterized 211 as "Candidatus hamiltonella" by comparison to the Silva132 reference database were 212 re-analyzed by homology searches against the NCBI nr nucleotide database through 213 blast (Altschul et al., 1990) and found to be Pseudomonas, highlighting a potential 214 incorrect assignment in the reference database.

215 The most abundant bacterial Phyla observed across the fall armyworm gut samples 216 were Proteobacteria, Firmicutes, Bacteroidetes and a small proportion of Actinobacteria 217 (Fig.S1). OTUs clustering in the orders Enterobacteriales and Pseudomonadales were 218 predominant in the majority of the samples (Fig. 2).

We noticed that despite the high genus-level diversity between samples (Fig. 3), there were some similarities based on developmental stage and location. For example, there was a very high proportion of: 1) Pseudomonas in the two adult male samples from Chala, 2) Citrobacter in two larval samples from Kwale, 3) Lysinibacillus in two male samples from Kitale and 4) Enterococcus in two larval samples from Ngeria. It was noted that Stenotrophomonas, Sphingobacterium, Serratia, Pseudomonas, Morganella, Enterococcus and Delftia were detected in both larvae and adult samples. 
227 In one of the larval samples from the Ngeria site (Ngeria-I2), we observed an excessive 228 number of non-bacterial reads. Through homology searches against the NCBI nr 229 nucleotide database, these were found to be closely related to Metarhizium rileyi (Farl.) 230 Kepler, Rehner \& Humber (2014) (formerly Nomuraea rileyi), an entomopathogenic 231 fungus that is known to infect S. frugiperda (Fig. 4).

233 The bacterial OTU richness appeared to be higher in S. frugiperda larvae than adults, 234 however this difference was not statistically significant ( $p$-value: 0.062526; [Mann235 Whitney] statistic: 19) using Shannon diversity metrics (Fig. 5a). In addition, no 236 significant variation in OTU richness and abundance was observed between larvae from 237 different sampling sites (p-value: 0.32834; [ANOVA] F-value: 1.3486) (Fig. 5b).

238 The composition of bacterial OTUs between larvae and adult S. frugiperda was 239 observed to overlap although some significant dissimilarity ([PERMANOVA] F-value: 240 2.734; R-squared: 0.26715; $p$-value $<0.001[N M D S$ ] Stress $=0.13859)$ was recorded 241 (Fig. 6). Similarly, OTU composition was observed to vary significantly among larval 242 samples from different sites ([PERMANOVA] F-value: 1.7511; R-squared: 0.36856; $p$ 243 value $<0.037$ [NMDS] Stress $=0.057109)($ Fig. 7$)$.

A significant differential abundance was observed for 3 bacterial genera between larvae 246 and adult $S$. frugiperda samples using the EdgeR algorithm at an adjusted $p$-value of 247 0.05. Two of these: Citrobacter $(\log 2 \mathrm{FC}=4.4178, \mathrm{p}$ value=3.6E-6, FDR=7.218E-5) and 248 Sphingobacterium $(\log 2 \mathrm{FC}=3.625, \mathrm{p}$ value $=1.01 \mathrm{E}-4, \mathrm{FDR}=0.0010118)$ were more 
249 abundant in larvae whereas the third: Lysinibacillus ( $\log 2 \mathrm{FC}=-3.2247, \mathrm{p}$ value $=4.4 \mathrm{E}-3$, 250 FDR=0.029375) was more abundant in adults (Fig. 8).

251

252 Based on mtDNA sequences, the $S$. frugiperda strains detected in this study were 253 identical to strains from Canada, USA and Brazil, as well as strains that were recently 254 reported in Kenya and parts of Africa and India (Fig. 9). All the samples clustered in two 255 major clades widely referred to as either the 'Rice' or the 'Corn' strain (hereafter referred 256 to as R- strain and C- strain). We investigated the frequency of mtDNA haplotypes of $S$. 257 frugiperda samples collected at several sites in Kenya. Overall, $90 \%$ of the samples $258(n=85)$ clustered as R-strain, whereas 10\% $(n=9)$ clustered as C-strain. Proportions of 259 the R-strain in populations at the different sites were 100\% $(n=6)$ for Burnt Forest, $83 \%$ $260(n=6)$ for Chala, 86\% ( $n=7)$ for Wundanyi, 82\% $(n=11)$ for Kitale, 91\% $(n=35)$ for Kwale 261 and $82 \%(n=17)$ for Ngeria (Fig. 10).

262

\section{Discussion}

264 We found that the gut bacterial communities of most $S$. frugiperda samples were 265 dominated by Proteobacteria. This observation is similar to proportions reported in other 266 phytophagous insects, in particular lepidopterans (Belda et al. 2011; Xia et al. 2013, 267 2017; Landry et al. 2015; Ramya et al. 2016; Snyman et al. 2016; Strano et al. 2017; 268 Chen et al. 2018). Only three samples, two adult males from Kitale (Kitale-m2 and 269 Kitale-m3) and one larva from Ngeria (Ngeria-12) were dominated by Firmicutes. The 270 four genera of bacteria, Pseudomonas, Delftia, Enterococcus and Serratia, that were 271 recorded in this study have previously been isolated from S. frugiperda (De Almeida et 
272 al. 2017; Acevedo et al. 2017). Surprisingly, Staphylococcus, Microbacterium, 273 Arthrobacter and Leclercia that were previously isolated from S. frugiperda in Brazil (De 274 Almeida et al., 2017) were not found in any of the samples we profiled in Kenya. 275 Similarly, Pantoea, Enterobacter, Raoultella and Klebsiella previously identified in oral 276 secretions of S. frugiperda in Pennsylvania, USA (Acevedo et al., 2017) were not found 277 in the profiled Kenyan samples. Six of the detected bacterial genera: Enterococcus, 278 Pseudomonas, Chryseobacterium, Sphingobacterium, Ochrobactrum and 279 Acinetobacter, have been detected using a similar sequencing approach in both $S$. 280 frugiperda as well as in the corn earworm Helicoverpa zea (Jones et al., 2018). 281 Similarly, seven of the detected bacterial genera: Enterococcus, Pseudomonas, 282 Comamonas, Stenotrophomonas, Eshcerichia-Shigella, Acinetobacter and 283 Carnobacterium, have been reported using a similar approach in the beet armyworm, $S$. 284 exigua (Gao et al., 2018). This suggests that some bacterial genera often associate with 285 lepidopteran insects, although it is difficult to define a core microbiota for such a diverse 286 insect order. The OTUs classified as Candidiatus hamiltonella using the Silva database were further investigated and reclassified as Pseudomonas. Candidiatus hamiltonella 288 has been recorded in whiteflies, psyllids and phloem-feeding relatives of the aphids (Russell \& Moran, 2005) but not among lepidopteran insects.

We observed significant differences in OTU composition between larvae from different 292 sites. This was most likely caused by complex biological and environmental factors in 293 the diverse agro-ecological zones that were sampled. Diet is known to strongly 294 influence the microbiome of lepidopterans (Strano et al. 2017; Sittenfeld et al. 2002; 
295 Priya et al. 2012; Montagna et al. 2016), however in this study all samples were 296 collected from maize plants. Hence, the observed compositional differences are not 297 likely to be caused solely by diet. It is interesting that many of the detected bacterial 298 genera such as Stenotrophomonas, Sphingobacterium, Serratia, Pseudomonas, 299 Morganella, Enterococcus and Delftia were found in both life stages, which suggests 300 that gut bacterial community members are transmitted across developmental stages. 301 Bacteria that are continually transmitted across developmental stages (and across 302 generations) may evolve a closer, mutualistic relationship with their hosts (Moran 2006).

303 Future studies should investigate the effects of these microbes on host fitness and 304 investigate the extent to which they are vertically transmitted from parents to offspring.

305 In contrast, Citrobacter and Sphingobacterium were observed to be differentially 306 abundant in larvae than in adults, a likely indicator that these two genera may be part of 307 the fraction of bacterial communities that are lost during transition of $S$. frugiperda into 308 the adult stage. Lysinibacillus, on the other hand, was more abundant in adults than in 309 larvae and therefore could have an adult-specific function.

311 Notably, we identified Serratia, Lysinibacillus (formerly Bacillus) and Pseudomonas, 312 species of which have been reported to have entomopathogenic properties (Castagnola 313 \& Stock, 2014). In addition, one sample had a high number of reads attributed to a 314 relative of a fungal entomopathogen, Metarhizium rileyi, which previously has been 315 isolated and tested for efficacy against S. frugiperda (Maniania and Fargues 1985;

316 Mallapur et al. 2018). However, there was no record of the use of any fungal

317 biopesticides in any of the sampled sites. This detection could however be an indication 
318 that $S$. frugiperda might be refractory to the fungus, in which case such a fungus could

319 be exploited in alternative control techniques such as in the delivery of dsRNA. It may

320 be worthwhile to re-examine the pathogenicity of these microbes for $S$. frugiperda and

321 to determine if they could be incorporated into biological pest management strategies 322 (Ruiu, 2015).

323

324 Based on the mtCOI gene sequences, we observed two mtDNA haplotypes in Kenya

325 (Corn and Rice strains), despite the fact that all of these insects were obtained from

326 maize. These findings confirm that both haplotypes are present in Kenya, as has been

327 demonstrated for other countries in Africa (Rwomushana et al., 2018). The majority of

328 the S. frugiperda samples collected were characterized as R-strain suggesting that this

329 strain is dominant in S. frugiperda populations in Kenya. These observations are in

330 agreement with a previous study (Nagoshi et al., 2018) that observed that Corn and

331 Rice strains appear to have an East-West axis alignment in the African region, with

332 Eastern Africa having progressively lower frequencies of the C-strain (Nagoshi et al.,

333 2018). We noted that some variants of the R-strain have been reported in other places

334 such as Ghana and India, but those variants were not detected in this study. It is

335 interesting to note that in addition to an R-strain similar to the one detected in Kenya, a

336 variant differing by a single nucleotide polymorphism in the sequenced region of the

$337 \mathrm{mtCO}$ gene has been recorded from various locations in India. This variant has

338 however not been reported in Africa. It is therefore possible that the invasion into India

339 may not have come directly from the African continent, or invasion could have included

340 strains from Africa and elsewhere. 


\section{Conclusions}

343 We characterized the gut bacterial communities in S. frugiperda larvae and adult

344 samples collected from several locations in Kenya, finding some important differences

345 and similarities across samples and in relation to other studies on this species (Acevedo 346 et al. 2017; De Almeida et al. 2017). Characterizing the gut microbial symbionts of this

347 pest species in Africa can be seen as an important first step towards the development of

348 novel, cost-effective symbiont and entomopathogen-based control strategies. In

349 addition, the population structure of this pest in Kenya was investigated. Understanding

350 the population structure, dynamics and bio-ecology of invasive species is important for

351 identifying their invasion patterns and for informing cropping systems especially where

352 pest species compositions associate with different host plant usage.

354 Acknowledgements

355 Authors acknowledge the technical support of Mr. Peter Malusi during sampling.

357 References

358 Acevedo FE, Peiffer M, Tan C-W, Stanley BA, Stanley A, Wang J, Jones AG, Hoover K, 359 Rosa C, Luthe D, Felton G. 2017. Fall armyworm-associated gut bacteria modulate 360 plant defense responses. Molecular Plant-Microbe Interactions 30:127-137. DOI:

361 10.1094/MPMI-11-16-0240-R.

362 De Almeida LG, De Moraes LAB, Trigo JR, Omoto C, Cônsoli FL. 2017. The gut microbiota of insecticide-resistant insects houses insecticide-degrading bacteria: a 
potential source for biotechnological exploitation. PLoS ONE 12:1-19. DOI: 10.1371/journal.pone.0174754.

Altschul SF, Gish W, Miller W, Myers EW, Lipman DJ. 1990. Basic local alignment search tool. Journal of Molecular Biology 215:403-410.

Amir A, McDonald D, Navas-Molina, Jose A. Kopylova E, Morton JT, Xu ZZ, Kightley EP, Thompson LR, Hyde ER, Gonzalez A, Rob K. 2017. Deblur rapidly resolves single-nucleotide community sequence patterns. mSystems 2:1-7.

Anand AAP, Vennison SJ, Sankar SG, Prabhu DIG, Vasan PT, Raghuraman T, Geoffrey CJ, Vendan SE. 2010. Isolation and characterization of bacteria from the gut of Bombyx mori that degrade cellulose, xylan, pectin and starch and their impact on digestion. Journal of Insect Science 10:1-20. DOI: 10.1673/031.010.10701.

Andrews S. 2010. FastQC: a quality control tool for high throughput sequence data.

Arora AK, Douglas AE. 2017. Hype or opportunity? Using microbial symbionts in novel strategies for insect pest control. Journal of Insect Physiology 103:10-17. DOI: 10.1016/j.jinsphys.2017.09.011.

Banerjee R, Hasler J, Meagher R, Nagoshi R, Hietala L, Huang F, Narva K, JuratFuentes JL. 2017. Mechanism and DNA-based detection of field-evolved resistance to transgenic Bt corn in fall armyworm (Spodoptera frugiperda). Scientific Reports 7:1-10. DOI: 10.1038/s41598-017-09866-y.

Beck JJ, Vannette RL. 2017. Harnessing insect-microbe chemical communications to 385 control insect pests of agricultural systems. Journal of Agricultural and Food Chemistry 65:23-28. DOI: 10.1021/acs.jafc.6b04298. 
387 Belda E, Pedrola L, Peretó J, Martínez-Blanch JF, Montagud A, Navarro E, Urchueguía 388 J, Ramón D, Moya A, Porcar M. 2011. Microbial diversity in the midguts of field and 389

Biere A, Bennett AE. 2013. Three-way interactions between plants, microbes and lab-reared populations of the European corn borer Ostrinia nubilalis. PLoS ONE insects. Functional Ecology 27:567-573. DOI: 10.1111/1365-2435.12100.

Boylen E, Rideout JR, Dillon MR, Bokulich NA, Abnet C, Ghalith GA Al, Alexander H, 394 Alm EJ, Arumugam M, Bai Y, Bisanz JE, Bittinger K, Brejnrod A, Colin J, Brown CT, Callahan BJ, Mauricio A, Rodríguez C, Chase J, Cope E, Silva R Da, Dorrestein PC, Douglas GM, Duvallet C, Edwardson CF, Ernst M, Fouquier J, Gauglitz JM, Gibson DL, Gonzalez A, Huttley GA, Janssen S, Jarmusch AK, Kaehler BD, Kang K Bin, Keefe CR, Keim P, Kelley ST, Ley R, Loftfield E, Marotz C, Martin B, Mcdonald D, Mciver LJ, Alexey V, Metcalf JL, Morgan SC, Morton JT, Naimey AT. 2018. QIIME 2: reproducible, interactive, scalable, and extensible microbiome data science. PeerJ Preprints. DOI: 10.7287/peerj.preprints.27295.

Brady CM, White JA. 2013. Cowpea aphid (Aphis craccivora) associated with different host plants has different facultative endosymbionts. Ecological Entomology:1-5. DOI: 10.1111/een.12020.

Broderick N, Raffa K, Goodman R, Handelsman J. 2004. Census of the bacterial community of the gypsy moth larval midgut by using culturing and cultureindependent methods. Applied and Environmental Microbiology 70:293-300. DOI:

409 Broderick AN, Raffa KF, Handelsman J. 2006. Midgut bacteria required for Bacillus 
thuringiensis insecticidal activity. PNAS 103:15196-15199. DOI: 10.1371/journal.pone.0170933.

412 Castagnola A, Stock SP. 2014. Common virulence factors and tissue targets of 413 entomopathogenic bacteria for biological control of Lepidopteran pests. insects $414 \quad$ 5:139-166. DOI: 10.3390/insects5010139.

415 Chen B, Du K, Sun C, Vimalanathan A, Liang X, Li Y, Wang B, Lu X, Li L, Shao Y. 416 2018. Gut bacterial and fungal communities of the domesticated silkworm (Bombyx 417 mori) and wild mulberry-feeding relatives. ISME Journal 12:2252-2262. DOI: $418 \quad 10.1038 / s 41396-018-0174-1$.

419 Crotti E, Balloi A, Hamdi C, Sansonno L, Marzorati M, Gonella E, Favia G, Cherif A, 420 Bandi C, Alma A, Daffonchio D. 2012. Microbial symbionts: a resource for the 421 management of insect-related problems. Microbial Biotechnology 5:307-317. DOI:

427 Deole S, Paul N. 2018. First report of fall army worm, Spodoptera frugiperda (J. E. 428 Smith), their nature of damage and biology on maize crop at Raipur, Chhattisgarh. 429 Journal of Entomology and Zoology Studies 6:219-221.

430 Dhariwal A, Chong J, Habib S, King IL, Agellon LB, Xia J. 2017. MicrobiomeAnalyst: A 431 web-based tool for comprehensive statistical, visual and meta-analysis of 432 microbiome data. Nucleic Acids Research 45:W180-W188. DOI: 
10.1093/nar/gkx295.

434 Douglas AE. 2009. The microbial dimension in insect nutritional ecology. Functional $435 \quad$ Ecology 23:38-47. DOI: 10.1111/j.1365-2435.2008.01442.x.

436 Douglas AE. 2016. Multiorganismal insects: diversity and function of resident 437 microorganisms. Annu Rev Entomol 60:17-34. DOI: 10.1146/annurev-ento$438 \quad 010814-020822$.

439 FAO. 2018. Sustainable management of the fall armyworm in Africa: a framework for $440 \quad$ partnership. Rome, Italy.

441 Ferrari J, Vavre F, Lyon D. 2011. Bacterial symbionts in insects or the story of 442 443 communities affecting communities. Philosophical Transactions of the Royal

444 Flagel L, Lee YW, Wanjugi H, Swarup S, Brown A, Wang J, Kraft E, Greenplate J, 445 Simmons J, Adams N, Wang Y, Martinelli S, Haas JA, Gowda A, Head G. 2018. 446 Mutational disruption of the ABCC2 gene in fall armyworm, Spodoptera frugiperda, confers resistance to the Cry1Fa and Cry1A.105 insecticidal proteins. Scientific Reports 8:1-11. DOI: 10.1038/s41598-018-25491-9.

Folmer O, Black M, Hoeh W, Lutz R, Vrijenhoek R. 1994. DNA primers for amplification

Frago E, Dicke M, Godfray HCJ. 2012. Insect symbionts as hidden players in insectof mitochondrial cytochrome c oxidase subunit I from diverse metazoan invertebrates. Molecular Marine Biology and Biotechnology 3:294-299. DOI: 10.1371/journal.pone.0013102. plant interactions. Trends in Ecology \& Evolution 27:705-711. DOI: 10.1016/j.tree.2012.08.013. 
456 Gao X, Li W, Luo J, Zhang L, Ji J, Zhu X, Wang L, Cui J. 2018. Biodiversity of the 457 microbiota in Spodoptera exigua (Lepidoptera: Noctuidae). Journal of Applied 458 Microbiology 126:1199-1208. DOI: https://doi.org/10.1111/jam.14190.

459 Garcia ES, Castro DP, Figueiredo MB, Azambuja P. 2010. Immune homeostasis to 460 microorganisms in the guts of triatomines (Reduviidae) - a review. Memorias do $461 \quad$ Instituto Oswaldo Cruz 105:605-610.

462 Goergen G, Kumar PL, Sankung SB, Togola A, Tamò M. 2016. First report of outbreaks 463 464 465 466 467

Hammer TJ, H. Janzen D, Hallwachs W, Jaffe SP, Fierera N. 2017. Caterpillars lack a resident gut microbiome. PNAS 114:9641-9646. DOI: 10.1073/pnas.1707186114.

468

469

470

471

472

473

474

475

476

477

478

of the fall armyworm Spodoptera frugiperda (J E Smith) (Lepidoptera, Noctuidae), a new alien invasive pest in West and Central Africa. PLoS ONE 11:1-9. DOI:

10.1371/journal.pone.0165632.

Huber DM, Hugh-Jones ME, Rust MK, Sheffield SR, Simberloff D, Taylor CR. 2002.

Invasive pest species: impacts on agricultural production, natural resources and the environment. Council for agricultural science and technology 20:1-18.

Jakka SRK, Gong L, Hasler J, Banerjee R, Sheets JJ, Narva K, Blanco CA, JuratFuentes JL. 2016. Field-evolved mode 1 resistance of the fall armyworm to transgenic Cry1Fa-expressing corn associated with reduced Cry1Fa toxin binding andmidgut alkaline phosphatase expression. Applied and Environmental Microbiology 82:1023-1034. DOI: 10.1128/aem.02871-15.

Jones, AG, Mason CJ, Felton GW, Hoover K. (2019). Host plant and population source drive diversity of microbial gut communities in two polyphagous insects. Scientific Reports, 9:1-11. https://doi.org/10.1038/s41598-019-39163-9 
479 Kikuchi Y, Hayatsu M, Hosokawa T, Nagayama A, Tago K. 2012. Symbiont-mediated $480 \quad$ insecticide resistance. Proceedings of the National Academy of Sciences 481 109:8618-8622. DOI: 10.1073/pnas.1200231109/482 /DCSupplemental.www.pnas.org/cgi/doi/10.1073/pnas.1200231109.

483 Landry M, Comeau AM, Derome N, Cusson M, Levesque RC. 2015. Composition of the 484 spruce budworm (Choristoneura fumiferana) midgut microbiota as affected by 485 rearing conditions. PLOS ONE 10:1-11. DOI: 10.1371/journal.pone.0144077. 486

Mallapur CP, Naik AK, Hagari S, Praveen T, Patil RK. 2018. Potentiality of Nomuraea rileyi (Farlow) Samson against the fall armyworm, Spodoptera frugiperda (J E Smith) infesting maize. Journal of Entomology and Zoology Studies 6:1062-1067.

Maniania NK, Fargues J. 1985. Susceptibility of the fall armyworm, Spodoptera frugiperda, to the fungal pathogens Paecilomyces fumosoroseus and Nomuraea rileyi. The Florida Entomologist 68:178-183.

Martin M. 2011. Cutadapt removes adapter sequences from high-throughput sequencing reads. EMBnet.journal 17:10. DOI: 10.14806/ej.17.1.200.

Mclean AHC, Godfray HCJ. 2015. Evidence for specificity in symbiont- conferred protection against parasitoids. Proceedings of the Royal Society B: Biological Sciences 282:1-8.

Midega CAO, Pittchar JO, Pickett JA, Hailu GW, Khan ZR. 2018. A climate-adapted push-pull system effectively controls fall armyworm, Spodoptera frugiperda (J E Smith), in maize in East Africa. Crop Protection 105:10-15. DOI: 10.1016/j.cropro.2017.11.003.

Montagna M, Mereghetti V, Gargari G, Guglielmetti S, Faoro F, Locatelli D, Limonta L. 
502

503

504

505

506

507

508

509

510

511

512

513

514

515

516

517

518

519

520

521

522

523

524

2016. Evidence of a bacterial core in the stored products pest Plodia interpunctella: the influence of different diets. Environmental Microbiology 18:4961-4973.

Moran NA. 2006. Symbiosis. Current Biology 16:R866-871.

Nagoshi RN, Goergen G, Plessis HDu, van den Berg J, Meagher R. (2019). Genetic comparisons of fall armyworm populations from 11 countries spanning subSaharan Africa provide insights into strain composition and migratory behaviors. Scientific Reports, 9:1-11. DOI: 10.1038/s41598-019-44744-9

Nagoshi RN, Goergen G, Tounou KA, Agboka K, Koffi D, Meagher RL. 2018. Analysis of strain distribution, migratory potential, and invasion history of fall armyworm populations in northern Sub-Saharan Africa. Scientific Reports 8:3710. DOI: 10.1038/s41598-018-21954-1.

Nagoshi RN, Meagher RL. 2004. Behavior and distribution of the two fall armyworm host strains in Florida. Florida Entomologist, 87:440-449. DOI: 10.1653/00154040(2004)087[0440:badott]2.0.co;2

Perilla-henao LM, Casteel CL. 2016. Vector-borne bacterial plant pathogens: interactions with Hemipteran insects and plants. Frontiers in Plant Science 7:1-15. DOI: 10.3389/fpls.2016.01163.

Pinto-Tomás AA, Sittenfeld A, Uribe-Lorío L, Chavarría F, Mora M, Janzen DH, Goodman RM, Simon HM. 2011. Comparison of midgut bacterial diversity in tropical caterpillars (Lepidoptera: Saturniidae) fed on different diets. Environmental Entomology 40:1111-1122. DOI: 10.1016/S0140-6736(02)87727-3.

Priya NG, Ojha A, Kajla MK, Raj A, Rajagopal R. 2012. Host plant induced variation in gut bacteria of Helicoverpa armigera. PLoS ONE 7:1-10. DOI: 
10.1371/journal.pone.0030768.

526

527

528

529

530

531

532

533

534

535

536

537

538

539

540

541

542

543 544 Davis T, Day R, Early R, Godwin J, Gonzalez-Moreno P, Kansiime M, Kenis M, 545 Makale F, Mugambi I, Murphy S, Nunda W, Phiri N, Pratt C, Tambo J. 2018. Fall 546 armyworm: impacts and implications for Africa evidence note update, October 547 2018. DOI: $10.1564 / v 28$.

Quast C, Prusse EP, Yilmaz P, Gerken J, Schweer T, Yarza P, Peplies J, Glockner FO. 2013. The SILVA ribosomal RNA gene database project: improved data processing and web-based tools. Nucleic Acids Research 41:D590-D596. DOI:

10.1093/nar/gks1219.

Ramya SL, Venkatesan T, Srinivasa Murthy KS, Jalali SK, Verghese A. 2016. Detection of carboxylesterase and esterase activity in culturable gut bacterial flora isolated from diamondback moth, Plutella xylostella (Linnaeus), from India and its possible role in indoxacarb degradation. Brazilian Journal of Microbiology 47:327-336. DOI:

10.1016/j.bjm.2016.01.012.

Robinson MD, McCarthy DJ, Smyth GK. 2009. edgeR: A Bioconductor package for differential expression analysis of digital gene expression data. Bioinformatics 26:139-140. DOI: 10.1093/bioinformatics/btp616.

Ruiu L. 2015. Insect pathogenic bacteria in integrated pest management. Insects 6:352-367. DOI: 10.3390/insects6020352.

Russell JA, Moran NA. 2005. Horizontal transfer of bacterial symbionts heritability and fitness effects in a novel aphid host. Applied and Environmental Microbiology 71:7987-7994. DOI: 10.1128/AEM.71.12.7987.

Rwomushana I, Bateman M, Beale T, Beseh P, Cameron K, Chiluba M, Clottey V, 
548 Sisay B, Simiyu J, Malusi P, Likhayo P, Mendesil E, Elibariki N, Wakgari M, Ayalew G,

549 Tefera T. 2018. First report of the fall armyworm, Spodoptera frugiperda

550 (Lepidoptera: Noctuidae), natural enemies from Africa. Journal of Applied

$551 \quad$ Entomology 142:800-804. DOI: 10.1111/jen.12534.

552 Sisodiya DB, Raghunandan BL, Bhatt NA, Verma HS, Shewale CP, Timbadiya BG,

553 Borad PK. 2018. The fall armyworm, Spodoptera frugiperda (J. E. Smith)

554 (Lepidoptera: Noctuidae); first report of new invasive pest in maize fields of Gujarat,

555 India. Journal of Entomology and Zoology Studies 6:2089-2091.

556 Sittenfeld A, Uribe-lorío L, Mora M, Nielsen V, Arrieta G, Janzen DH. 2002. Does a

557 polyphagous caterpillar have the same gut microbiota when feeding on different

558 species of food plants? Revista de Biologia Tropical 50:547-560.

559 Strano CP, Malacrinò A, Campolo O, Palmeri V. 2017. Influence of host plant on

560 Thaumetopoea pityocampa gut bacterial community. Microbial Ecology 75:487-

561 494. DOI: $10.1007 / \mathrm{s} 00248-017-1019-6$.

562 Su Q, Zhou X, Zhang Y. 2013. Symbiont-mediated functions in insect hosts.

$563 \quad$ Communicative and Integrative Biology 6:e23804 1-7. DOI:

564 https://doi.org/10.4161/cib.23804.

565 Ubeda C, Djukovic A, Isaac S. 2017. Roles of the intestinal microbiota in pathogen

566 protection. Clinical and translational immunology 6:1-10. DOI: 10.1038/cti.2017.2.

567 Wang J, Peiffer M, Hoover K, Rosa C, Zeng R, Felton GW. 2017. Helicoverpa zea gut-

$568 \quad$ associated bacteria indirectly induce defenses in tomato by triggering a salivary

569 elicitor(s). New Phytologist 214:1294-1306. DOI: 10.1111/nph.14429.

570 Wei G, Lai Y, Wang G, Chen H, Li F, Wang S. 2017. Insect pathogenic fungus interacts 
571 with the gut microbiota to accelerate mosquito mortality. PNAS 114:5994-5999.

$572 \quad$ DOI: 10.1073/pnas.1703546114.

573 Xia X, Gurr GM, Vasseur L, Zheng D, Zhong H, Qin B, Lin J, Wang Y, Song F, Li Y, Lin

$574 \quad$ H, You M. 2017. Metagenomic sequencing of diamondback moth gut microbiome

575 unveils key holobiont adaptations for herbivory. Frontiers in Microbiology 8:1-12.

$576 \quad$ DOI: 10.3389/fmicb.2017.00663.

577 Xia X, Sun B, Gurr GM, Vasseur L, Xue M, You M. 2018. Gut microbiota mediate

578 insecticide resistance in the diamondback moth, Plutella xylostella (L.). Frontiers in

579 Microbiology 9:1-10. DOI: 10.3389/fmicb.2018.00025.

580 Xia X, Zheng D, Zhong H, Qin B, Gurr GM, Vasseur L, Lin H, Bai J, He W, You M. 2013.

581 DNA sequencing reveals the midgut microbiota of diamondback moth, Plutella

$582 \quad x y l o s t e l l a(L$.$) and a possible relationship with insecticide resistance. PLoS ONE$

583 8:1-8. DOI: 10.1371/journal.pone.0068852.

584 Xiang H, Wei G-F, Jia S, Huang J, Miao X-X, Zhou Z, Zhao L-P, Huang Y-P. 2006.

585 Microbial communities in the larval midgut of laboratory and field populations of

586 cotton bollworm (Helicoverpa armigera). Canadian Journal of Microbiology

587 52:1085-1092. DOI: 10.1139/W06-064.

588 Yu SJ. 1991. Insecticide resistance in the fall armyworm, Spodoptera frugiperda.

589 Pesticide Biochemistry and Physiology 39:84-91. 
Figure 1

Sites from which Spodoptera frugiperda larvae were collected in Kenya. 


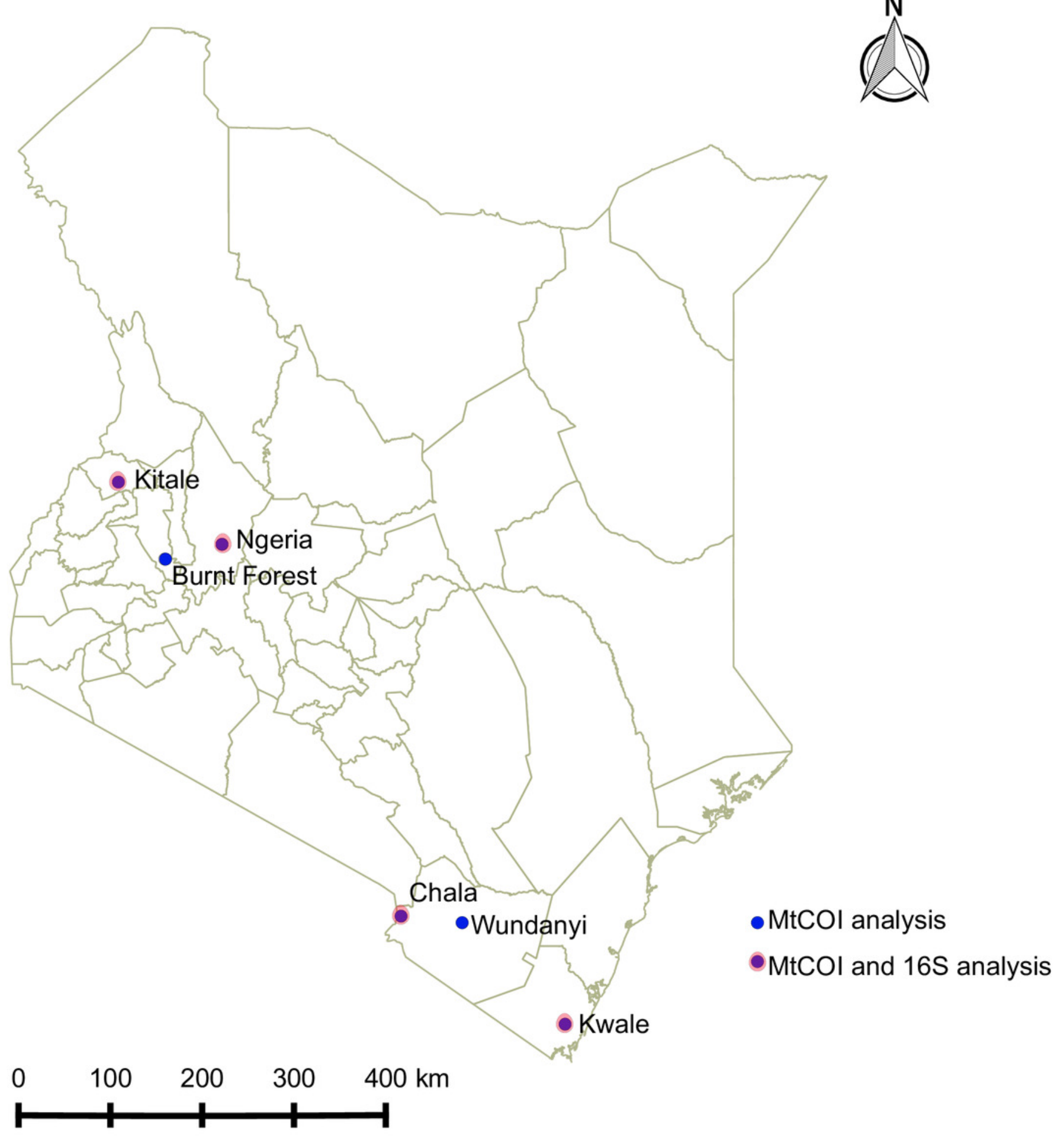


Figure 2

Composition of bacterial OTUs at Order level in screened Spodoptera frugiperda samples.

Samples are denoted as "site name-developmental stage/sex_sample number", where; $\mathrm{I}=$ larvae, $\mathrm{m}=$ male and $\mathrm{f}=$ female.
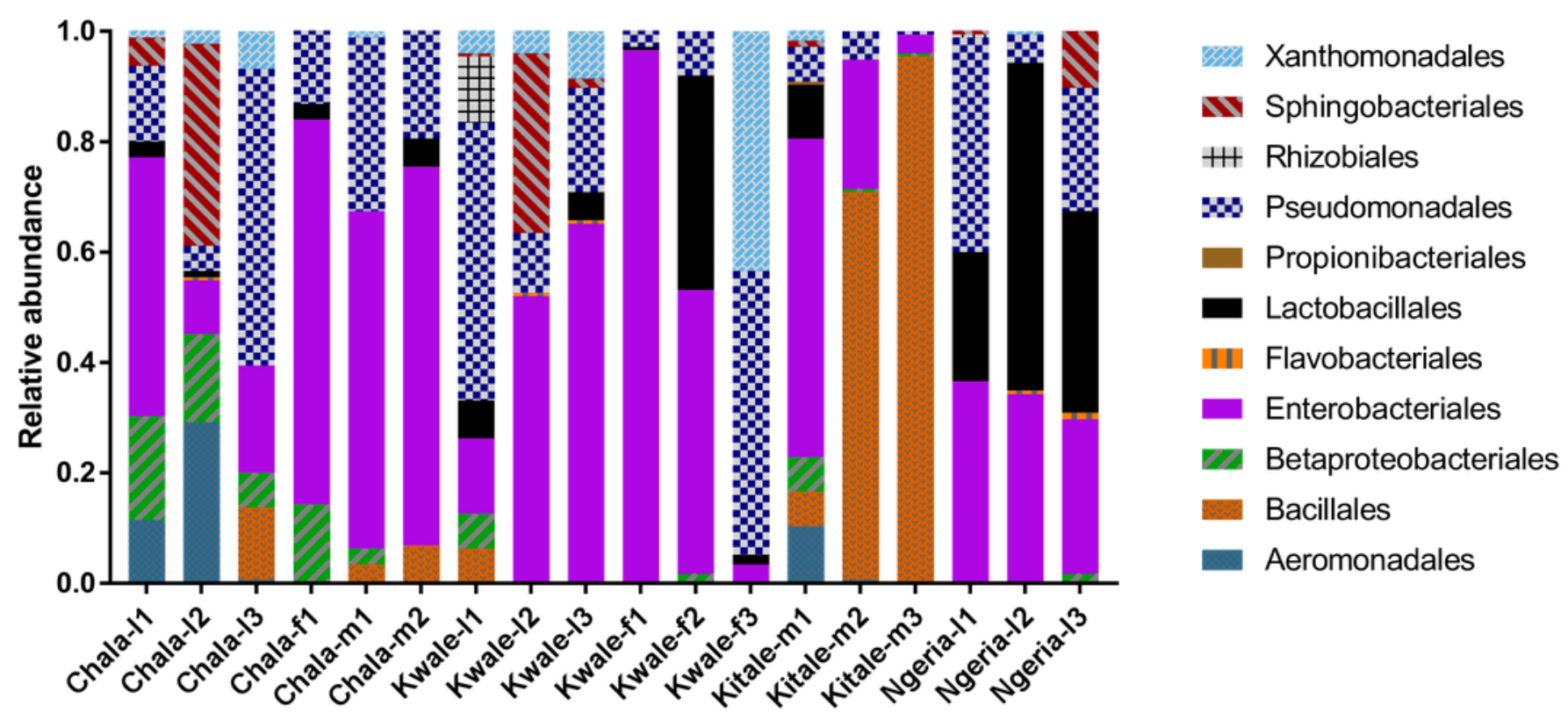
Figure 3

Genus level composition of (\% of OTUs) in the different samples of S. frugiperda.

Samples are denoted as "site name-developmental stage/sex_sample number", where; $\mathrm{I}=$ larvae, $\mathrm{m}=$ male and $\mathrm{f}=$ female. The relative abundances of the 19 most abundant genera (with more than 10 counts after low count and variance filtering) are represented here.

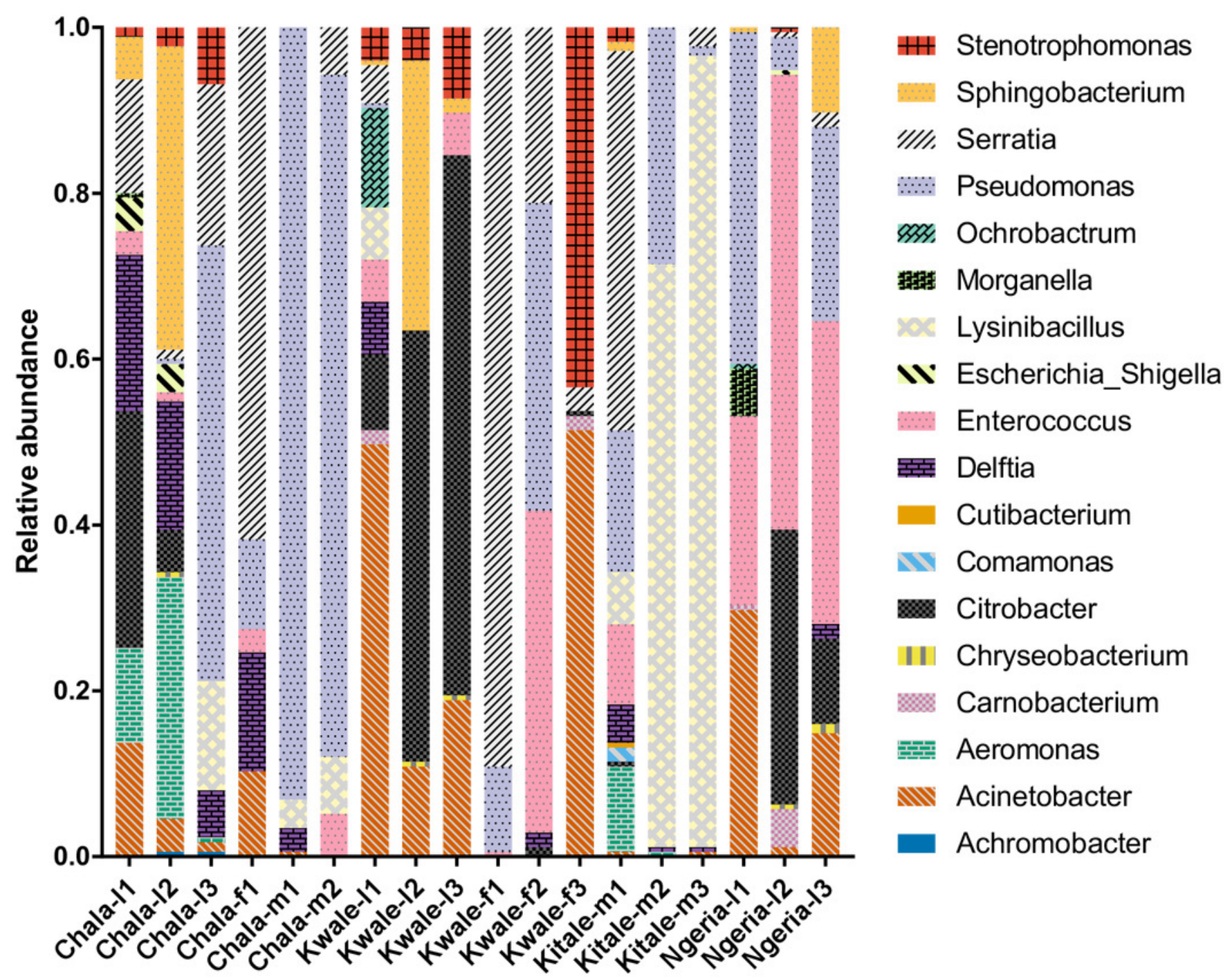




\section{Figure 4}

Neighbor-joining tree of fungus OTU detected in S. frugiperda sample (Ngeria-I2; in bold) and GenBank accessions of small subunit ribosomal RNA gene sequences from related fungi.

Sequences are labelled by their GeneBank Accessions followed by genus, species and strain where available. Bootstrap values are indicated above the branches. Branches with a bootstrap value less than 50 are collapsed. A sequence from a species in the genus Rozella is included as an out-group. 


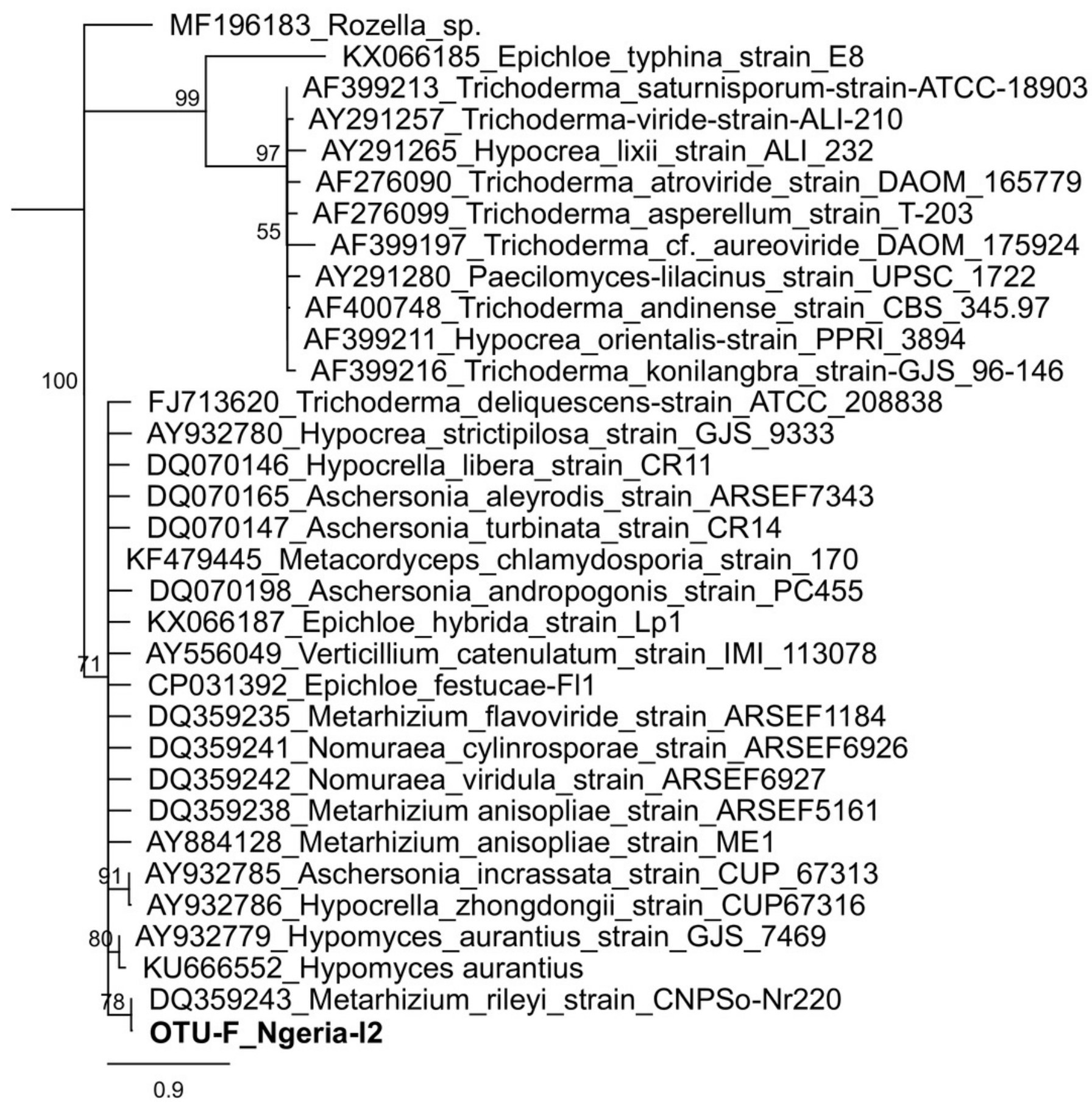


Figure 5

A comparison of the Shannon diversity indices for: (a) adult and larval samples from all sites and (b) larvae collected from different sites.

The Shannon diversity index ( $\mathrm{H}^{\prime}$ ) was calculated based on the OTU-level of classification. The boxplots show the distribution of $\mathrm{H}^{\prime}$ values across all samples.

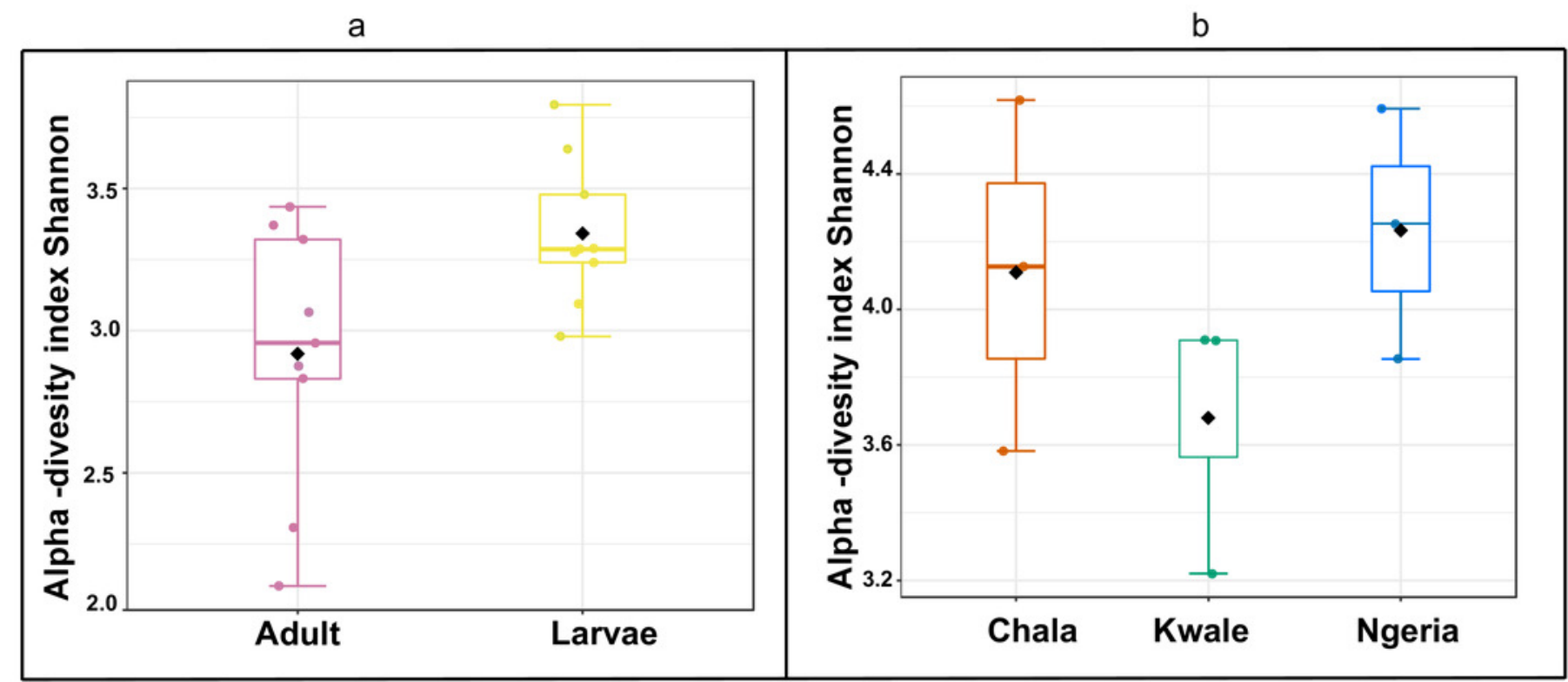

(p-value: 0.062526; [Mann-Whitney] statistic: 19) 
Figure 6

Non-metric multidimensional scaling (NMDS) ordination based on Bray-Curtis dissimilarities in bacterial communities detected in the $S$. frugiperda samples.

Samples are colored according to their developmental stage and sex as indicated on the legend where $\mathrm{F}=$ female, $\mathrm{L}=$ larvae and $\mathrm{M}=$ male.

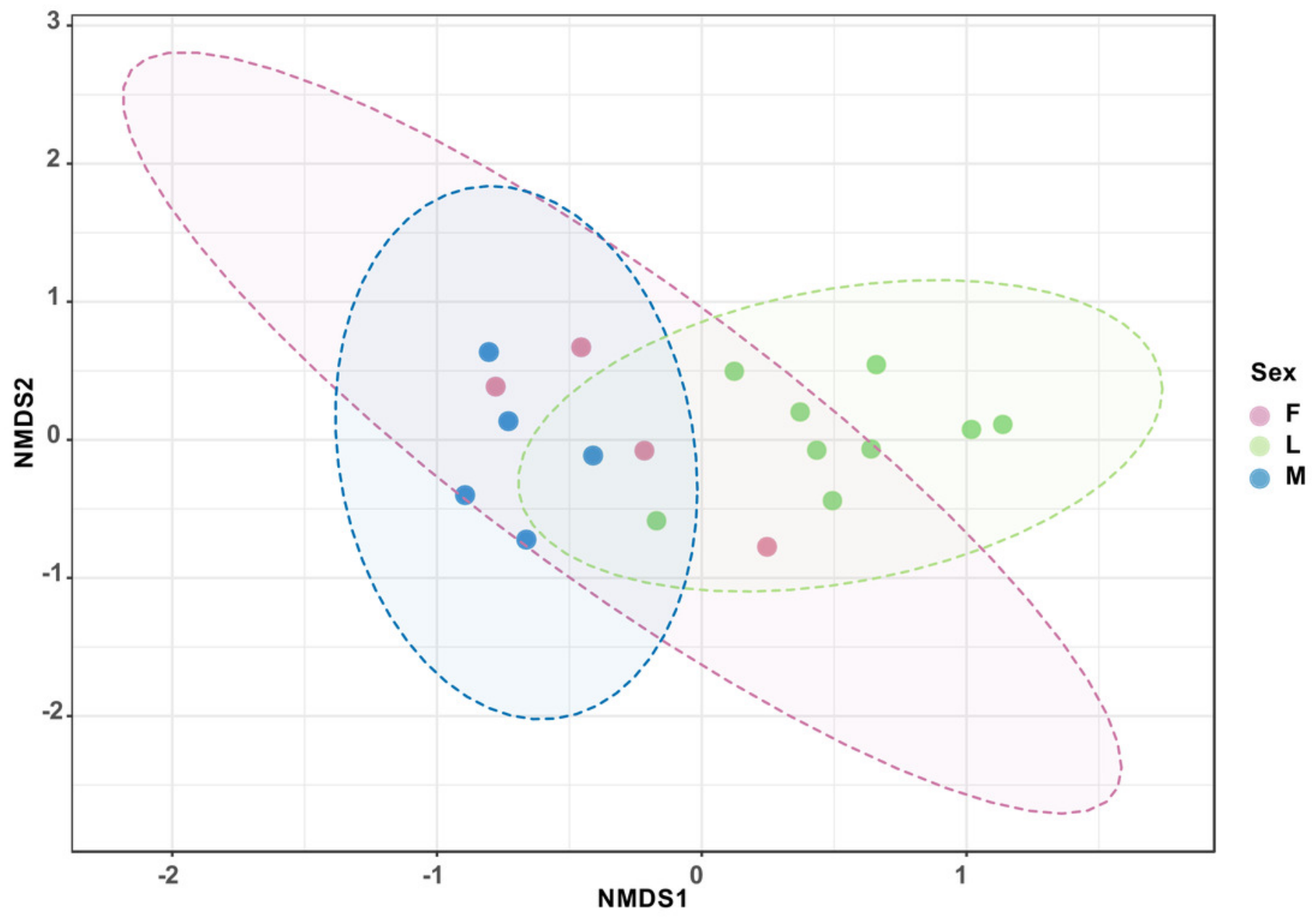

[PERMANOVA] F-value: $2.734 ;$ R-squared: $0.26715 ; p$-value $=0.001$ [NMDS] Stress $=0.13859$ 
Figure 7

Non-metric multidimensional scaling (NMDS) ordination based on Weighted Unifrac distance dissimilarities in bacterial OTU composition between larval sample pairs from different sites.

Samples are labelled by their collection site identifiers.

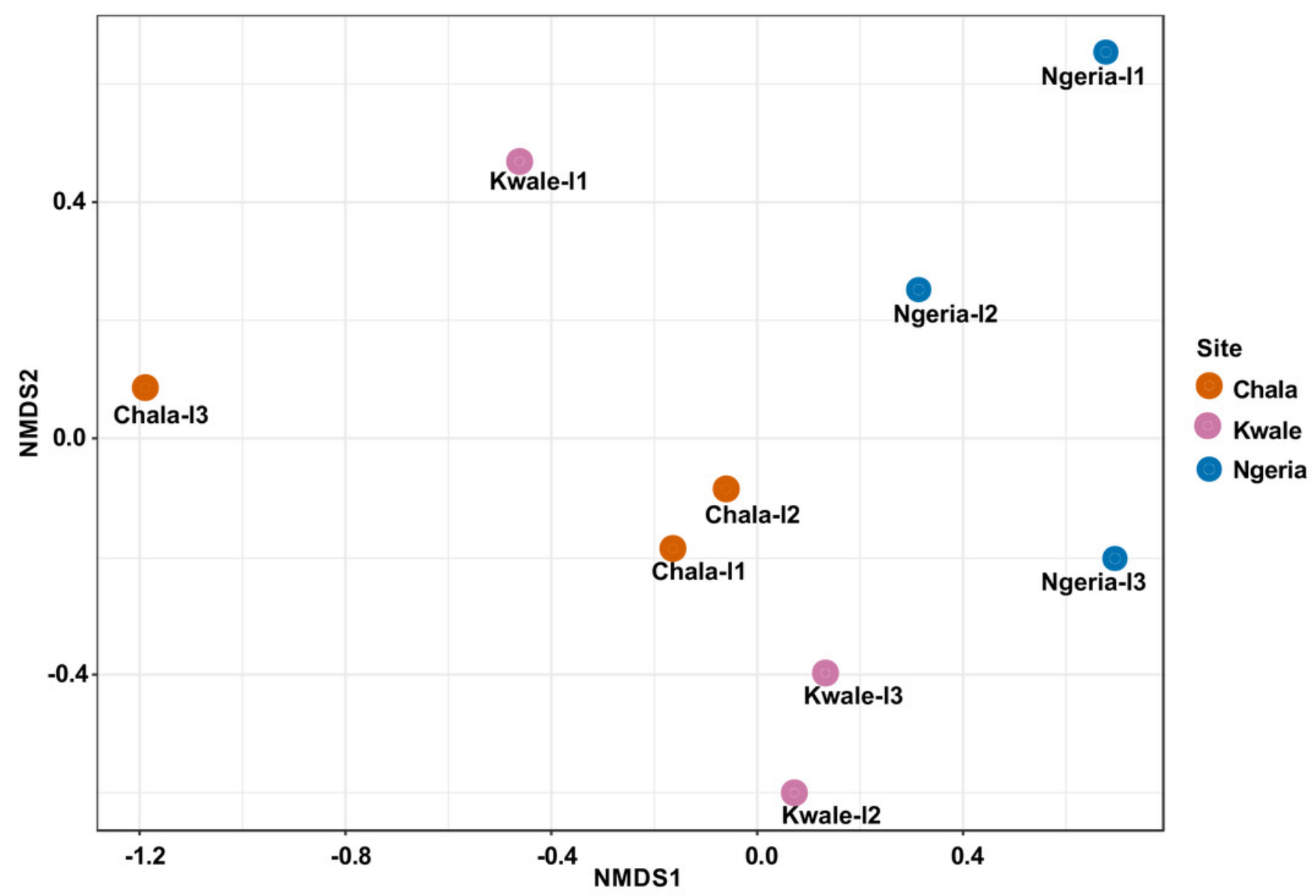

[PERMANOVA] F-value: $1.7511 ;$ R-squared: $0.36856 ; p$-value $=0.037$ [NMDS] Stress $=0.057109$ 
Figure 8

Comparative abundance of A) Citrobacter, B) Lysinibacillus and C) Sphingobacterium between adults and larvae of $S$. frugiperda.

Abundance is shown on a log transformed scale of original counts

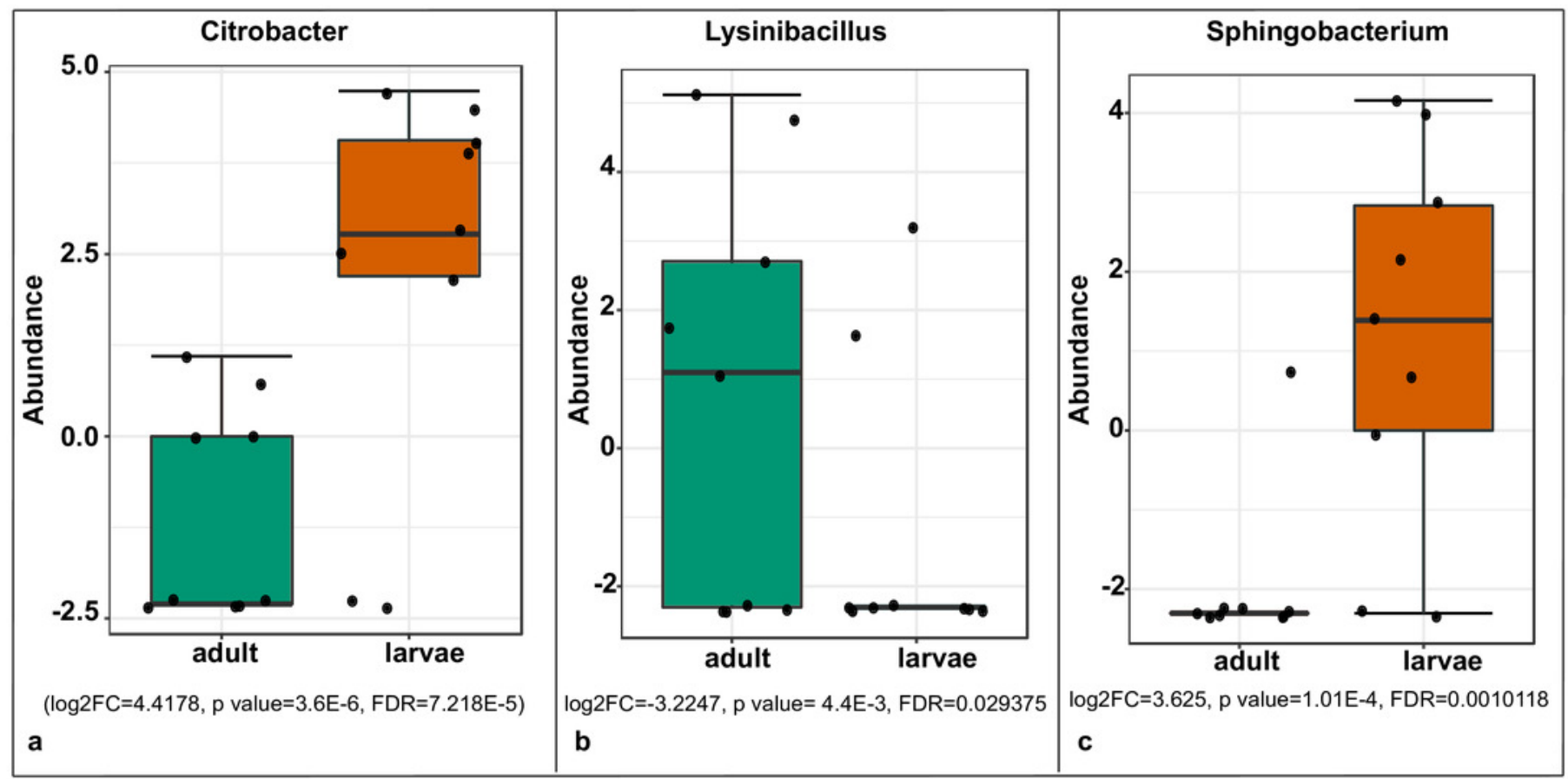


Figure 9

Neighbor-joining tree based on mtCOI sequences of $S$. frugiperda from the GenBank and representative haplotypes from this study (in bold).

Bootstrap values are indicated above branches. Branches with bootstrap values less than 50 are collapsed. A sequence from Spodoptera exigua is included as an out-group. Sequences are labelled with their GenBank accession numbers, collection site where available and country of collection. 


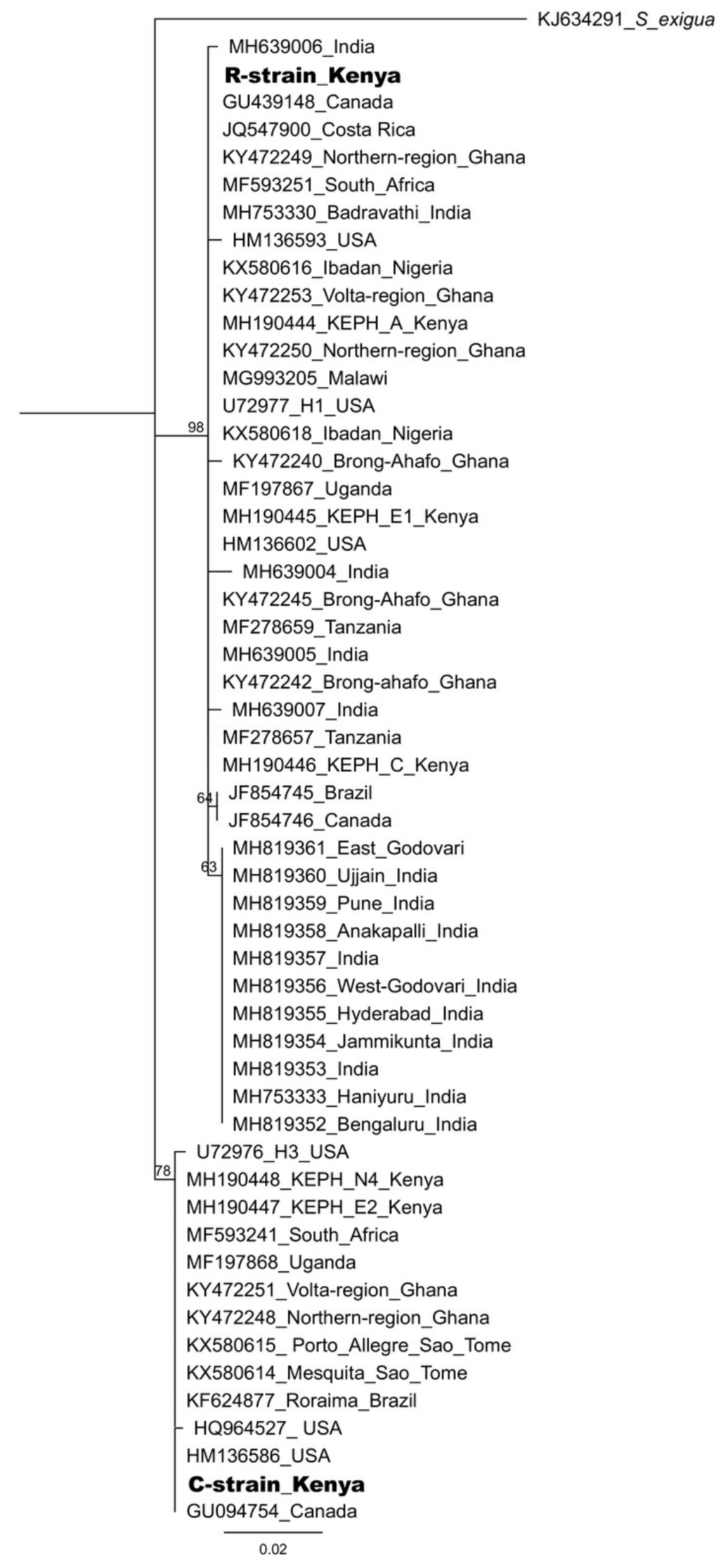




\section{Figure 10}

Mitochondrial COI haplotype map of the S. frugiperda samples collected at various sites in Kenya.

Node size is proportional to number of samples and individual samples are represented as fractions of the nodes. A sequence of Spoladea recurvalis is included as an out-group.

Sequences for all samples are accessible from GenBank using the accessions: MK492929MK493010.
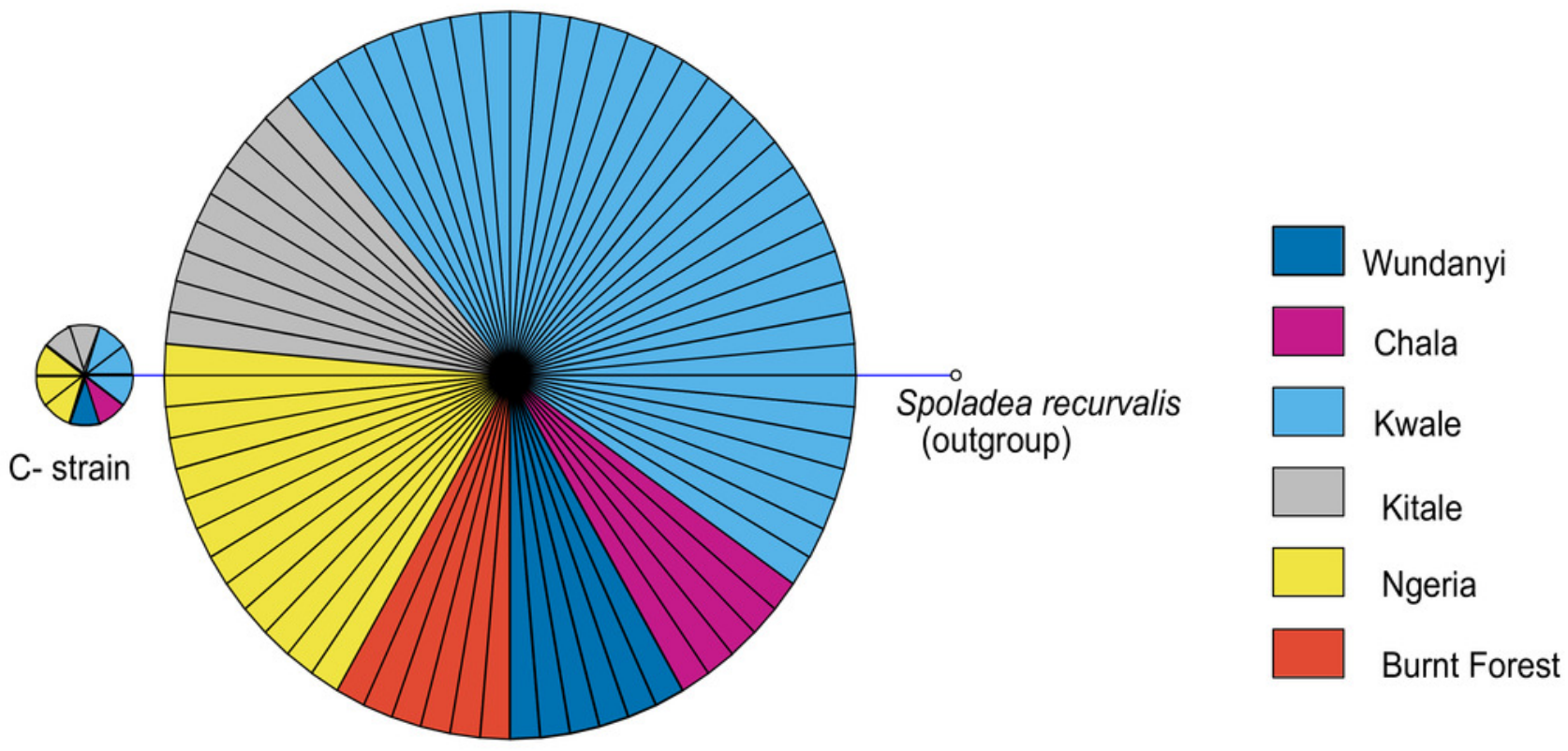

R-strain 